\title{
Lymph Node Fine-Needle Cytology: Beyond Flow Cytometry
}

\author{
Anna Lucia Peluso ${ }^{a}$ b Antonio leni ${ }^{c}$ Chiara Mignognad Pio Zeppa ${ }^{e}$ \\ ${ }^{a}$ Department of Medicine and Surgery, University of Salerno, Baronissi, ${ }^{b}$ Department for Energy and Environment, \\ University 'G. Marconi' of Rome, Rome, 'Department of Human Pathology, University of Messina, Messina, \\ 'Department of Health Sciences, University 'Magna Graecia' of Catanzaro, Catanzaro, and 'Department of Pathology, \\ Hospital 'San Giovanni di Dio e Ruggi d'Aragona' of Salerno, Salerno, Italy
}

\section{Key Words}

Flow cytometry · High-throughput technologies .

Next-generation sequencing - Polymerase chain reaction . IGH/T-cell receptor clonality tests - Lymph node cytology .

Fine-needle cytology

\begin{abstract}
Lymph node (LN) fine-needle cytology (FNC) coupled with flow cytometry immunophenotyping provides relevant information for the diagnosis of non-Hodgkin lymphoma (NHL). Numerous studies have shown FNC samples to be suitable for different molecular procedures; in this review, some of the molecular procedures most commonly employed for NHL are briefly described and evaluated in this perspective. Fluorescence in situ hybridization and chromogenic in situ hybridization are briefly described. Polymerase chain reaction (PCR)-based assays are used to identify and quantify mutations and translocations, namely immunoglobulin (IGH) and T-cell receptor rearrangements by clonality testing and IGVH somatic hypermutations either by Sanger sequencing, single-strand conformational polymorphisms or RT-PCR strategies. High-throughput technologies (HTT) encompass numerous and different diagnostic tools that share the capacity of multiple molecular investigation
\end{abstract}

and sample processing in a fast and reproducible manner. $\mathrm{HTT}$ includes gene expression profiling, comparative genomic hybridization, single-nucleotide polymorphism arrays and next-generation sequencing technologies. A brief description of these tools and their potential application to LN FNC is reported. The challenge for FNC will be to achieve new knowledge and apply new technologies to FNC, exploiting its own basic qualities.

(c) 2016 S. Karger AG, Basel

\section{Introduction}

Since its introduction over 3 decades ago, flow cytometry (FC) immunophenotyping has provided relevant information for the diagnosis, classification and monitoring of hematological malignancies on blood, bone marrow, cerebrospinal fluid, lymph nodes (LNs) and extranodal fine-needle cytology (FNC) [1]. Regarding LN FNC, the FC data provided consist mainly of the clonality assessment of lymphoproliferative processes, the classification of corresponding entities, and prognostic and predictive information. The advantages and achievements of LN FNC and FC have been extensively reported in the literature and are summarized in the

\section{KARGER}

E-Mail karger@karger.com www.karger.com/acy
(C) 2016 S. Karger AG, Basel

0001-5547/16/0604-0365\$39.50/0
Correspondence to: Dr. Anna Lucia Peluso

Hospital 'San Giovanni di Dio e Ruggi d'Aragona' of Salerno via Largo Città di Ippocrate

IT-84131 Salerno (Italy)

E-Mail annalucia.peluso@gmail.com 


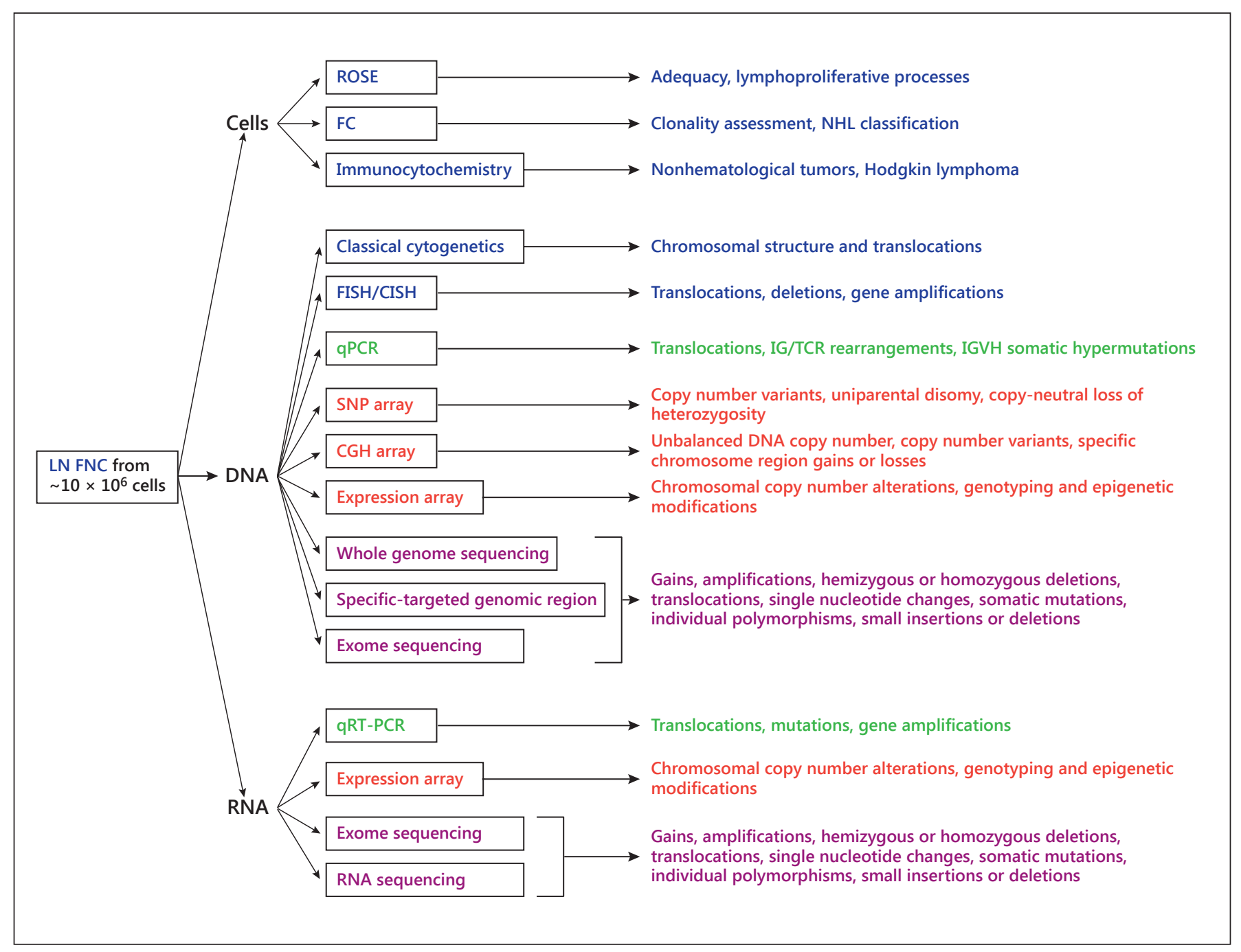

Fig. 1. Comprehensive overview of all the possible applications of LN FNC. All the procedures have been tested on FNC samples from different tumors, including lymphoma.

present issue; nonetheless, looking at the same data, specific limits of the procedure also emerge. In fact, despite a general high sensitivity in clonality assessment by light chain and specific phenotypes, a small but definite percentage of undefined cases occurs in all the series reported [2]. The accuracy rate in subtyping classifications of specific non-Hodgkin lymphoma (NHL) entities by LN FNC/FC also ranges between 51 and 95\%, with the unclassified cases only defined as B-cell or T-cell NHL [2-6]. In the meantime, spectacular progress in genetic and molecular knowledge and procedures has progressed the diagnostics of tumors, and specifically of NHL, toward a more individual definition of the single entities and personalized corresponding therapies.
Therefore, an accurate phenotypical definition of NHL, in addition to not being always feasible by FNC/FC, may be insufficient for diagnostic and predictive needs. Despite these limitations, FNC is still the most accessible, feasible, inexpensive, well-tolerated and effective procedure with which to obtain vital cells from LNs, without invasive procedures. An additional advantage of LN FNC is that its adequacy can be immediately assessed by rapid on-site evaluation (ROSE). Moreover, since chronic NHL diseases present with a high rate of relapses or concomitant reactive processes, FNC offers the opportunity to control the corresponding processes over time and in different sites, with a high homogeneity of the samples and minimal discomfort for patients. Numer- 


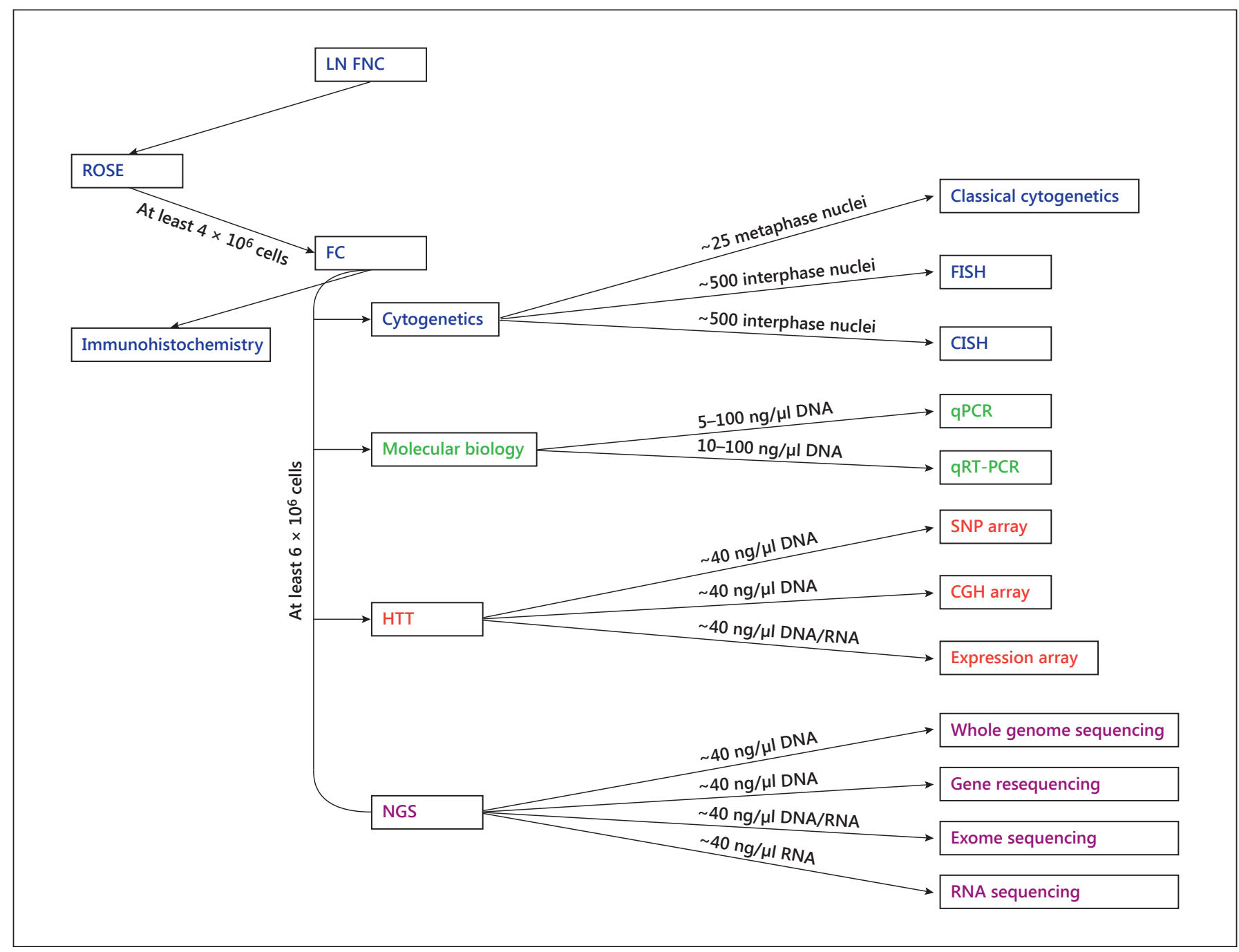

Fig. 2. Quantitative genetic material needed for LN FNC molecular testing. From an ideal harvesting of 10 million cells obtainable from 2-3 FNCs, the quantitative disposal of corresponding genetic material is reported.

ous studies have shown that FNC samples are suitable for different molecular procedures (fig. 1) [7, 8]. Even the drawback of the small amount of material obtained by FNC, which is the main limitation of this procedure, may be overcome by new technologies that are able to maximize the use of a few nanograms of good-quality genetic material (fig. 2) [7,8]. Therefore, once again, FNC may be conveniently used in NHL management, and the new challenge for cytopathologists, starting with FC/FNC and ROSE, will be to acquire updated knowledge and apply new technologies to FNC, exploiting its own basic qualities. In this review, some of the molecular procedures mostly utilized for NHL are briefly described and evaluated in this perspective.

\section{Cytogenetic Analysis}

Most NHLs are characterized by specific cytogenetic abnormalities and are routinely investigated using genetic tests, such as classical cytogenetics, fluorescence in situ hybridization (FISH) and chromogenic in situ hybridization (CISH) (fig. 1,2). These tests provide useful information regarding clonality, or distinctive chromosomal/molecular abnormalities associated with specific entities and lymphoid cell lineages, confirming NHL diagnosis - albeit with some exceptions and limitations [5, 9-18]. Classical cytogenetics include the routine analysis of G-banded chromosomes and other cytogenetic banding techniques for the study of cell structure and chromosomes. 
FISH is considered the gold standard for the detection of NHL primary karyotypic abnormalities. FISH, by using fluorescent probes that bind parts of the chromosomes with a high degree of sequence complementarity, can identify the most frequent translocations and gene region amplifications of specific NHL subtypes [11]. In the absence of specific translocations, FISH may also identify genes involved in rearrangements that are secondarily translocated to other chromosomes [11, 19]. Commercially available probes cover almost all the variable breakpoints of chromosomal alterations; as for their clinical applications, they are selected on the basis of initial clinical, (cyto)morphological and immunophenotypical data. FISH can be performed on tissues and any cytological sample, including LN FNC, where it is generally used after FNC/FC [3, 5, 9-18, 20-24]. FISH on interphase nuclei is generally performed using fusion-signal FISH probes, which consist of two fluoresceinated probes that hybridize two regions proximal to the breakpoint of the chromosomes involved in a supposedly reciprocal translocation $[3,5,10,12-14,16-18,20-24]$. In the absence of any chromosomal aberration, two pairs of distinct color signals are generally detected. Conversely, in the case of specific translocations involving the labeled loci, two differently labeled probes will juxtapose, giving fusion signals $[3,5,10,12-14,16-18,20-24]$. FISH has been successfully applied on LN FNC to detect specific chromosomal translocations in diffuse large B-cell lymphoma (DLBCL) [9], follicular lymphoma (FL) $[9,11,16$, 17, 23], mantle cell lymphoma (MCL) [9, 11, 22], small lymphocytic lymphoma/chronic lymphocytic leukemia (SLL/CLL) [9], marginal zone lymphoma [9], Burkitt lymphoma (BL) [9] and anaplastic large-cell lymphoma (ALCL) $[11,24]$. These studies have generally used one or two probes to identify a specific NHL subtype, namely IGH/BCL2 to detect the $\mathrm{t}(14 ; 18)(\mathrm{q} 32 ; \mathrm{q} 21.3)$ in FL; IGH/ CCND1 to detect the $t(11 ; 14)(\mathrm{q} 13 ; \mathrm{q} 32)$ in MCL; IGH/ MYC:CEP8 to detect $\mathrm{t}(8 ; 14)(\mathrm{q} 24 ; \mathrm{q} 32)$ (Dual Color Dual Fusion Probes) for BL; immunoglobulin (Ig)H, MALT1, MYC (Break Apart Probes), as well as the enumeration/ copy number probes CEP 3 (D3Z1), CEP 12 (D12Z3), 13q14 (D13S319), 13q34 (D13S25/LAMP1), ATM/ D11Z1 and 17p13 (TP53), and CEP17 (D17Z1). In DLBCL, FISH is used to identify BCL6 mutations (10\% of cases) [9] and translocations with numerous partners (20-30\% of cases) $[9,25]$, which may lead to overexpression of the BCL6 protein. In FL, FISH has detected twice as many $\mathrm{t}(14 ; 18)$ (BCL3-IGH@)-positive patients as polymerase chain reaction (PCR) assays [10] by disclosing the cryptic translocations producing overexpression of the

Lymph Node Fine-Needle Cytology:

Beyond Flow Cytometry
BCL2 protein $[9,26]$. In MCL, FISH has disclosed the degree of karyotypic complexity [11] determining not only the presence of the $t(11 ; 14)$ translocation, but also of the SOX11 alterations in CCND1 negativity, the gains of 3q and the losses of $17 \mathrm{p}$, which are associated with poor survival $[6,9,22,27-29]$. Conversely, FISH is not helpful in MCL cases where the $\mathrm{t}(11 ; 14)$ involves cyclin D2 or D3 [9]. In SLL/CLL, FISH is performed to detect 13q14 deletion, 11q22-23 deletion, trisomy 12q, 17p13 and 6q21 deletions, and ZAP70 expression. The latter is mainly useful in patients in advanced stages of the disease or those carrying the TP53 mutations, which are correlated to an unfavorable prognosis $[9,30]$. FISH also distinguishes SLL/ CLL from MCL, which share the CD5/CD19 cluster coexpression [10-14, 16, 17]. In ocular adnexa, salivary gland, and lung MALT, FISH may be useful to detect the IGH@-MALT1 [9], the $t(3 ; 14)(p 14.1 ; q 32)$ FOXP1IGH@, the t(1;14)(p22;q32) and the IGH@-BCL10, with the latter rarely being found in the lung, intestine, or salivary glands. BL generally shows a quite typical immunophenotype: CD10+ BCL6+ BCL2-, Ki67+ (100\%) [9]. FISH can confirm FC/FNC diagnosis by the detection of the $\mathrm{t}(8 ; 14)$ (q24;q32) involving MYC and IGH@, and the variant translocations involving MYC and the $\mathrm{j}$ or $\mathrm{k}$ light chain loci (2p12 and 22q11, respectively) in a minority of cases. Moreover, since the breakpoint sites of the translocations above described are widely dispersed, the use of standard PCR-based assays is precluded. Conversely, the FISH probes used for the identification of MYC translocations are more sensitive. As far as DLBCL is concerned, FISH can identify all of the more frequent translocations [9]. ALCL is characterized by $\mathrm{t}(2 ; 5)(\mathrm{p} 23 ; \mathrm{q} 35)$ involving NPM1 and ALK, resulting in the upregulation of ALK (a receptor tyrosine kinase). ALK overexpression may be detected by immunohistochemistry but, since different variants of ALK translocation have been identified, FISH uses an ALK break-apart probe suited to capture all of these abnormalities, as compared with RT-PCR [9]. On the other hand, FISH is not indicated in cases of ALKnegative ALCL for the lack of translocations involving ALK or any other recurrent genetic abnormality. In these cases, PCR may show clonal rearrangement of the T-cell receptor (TCR) genes, as in ALK+ ALCL [9].

$\mathrm{CISH}$ combines the chromogenic signal detection method of immunohistochemistry techniques with in situ hybridization [31]. This procedure was developed as an alternative to FISH for the detection of HER-2/neu oncogene amplification [31]. CISH is much more practical in diagnostic laboratories because it uses bright-field microscopes rather than the more expensive and complex 
fluorescence microscopes used in FISH [31]. CISH performed after FISH double checks the data provided by the latter; in addition, the persistence of a signal beyond the decay of the fluorescence allows a protracted reaction and a reevaluation of the sample [10]. CISH analysis on interphase nuclei is generally performed using split-signal FISH probes, which hybridize two regions of the same chromosome proximal to a supposed breakpoint. In normal cells, the two hybridized regions are proximal to each other, generating two fusion signals [10]. Split-signal FISH has some advantages over fusion-signal FISH; in fact, the detection of a translocation is independent of the partner genes involved and is useful for detecting translocations involving multiple partner genes, as is the case of the IGH locus at chromosome 14q32. What is generally considered another advantage of split-signal FISH is the absence of the false-positive cases reported using fusion-signal FISH probes [10]. The IGH locus is most frequently involved in different NHL translocations $[10,28$, $32,33]$, therefore the detection of any breakage involving the IGH locus at chromosome $14 \mathrm{q} 32$ should identify a Bcell NHL independently of the specific subtype on cytological samples. In this case, the split-signal IGH FISH/ CISH DNA probe is a mixture of two fluorochrome-labeled DNAs: a green fluorescein-labeled DNA probe (IGH-Flu) that binds to a 612-kilobase (kb) segment telomeric, and a red-labeled DNA probe (IGH-TR) that binds to a $460-\mathrm{kb}$ segment centromeric, both to the IGH breakpoint. In the case of a translocation involving the IGH locus, whatever the fate of the sequence detached, two distinct split signals are observed. Therefore, the split-signal IGH FISH/CISH DNA probe should be highly sensitive, detecting any translocation involving the IGH locus at chromosome $14 \mathrm{q} 32$ and assessing the clonality of the corresponding processes, although it is not specific for any of the corresponding NHL entities [10]. In fact, the IGH split probe, other than in FL and MCL, identifies two distinct split signals in $14 \%$ of malignant mesothelioma cases, $13 \%$ of CLL cases, and 50\% of DLBCL, 17\% of SLL/ CLL and $7 \%$ of marginal zone lymphoma cases $[10,34]$. Since the IGH split-signal DNA probe spans much of the constant and variable regions of the IGH, split signals should be generated even in cases of aberrant breakpoints. Another application of FISH/CISH assays is the identification of the so-called dual-translocation or double-hit lymphomas, which involve MYC and BLC2 rearrangements, with MYC thought to represent the second hit in a $t(14 ; 18)$-positive DLBCL. These cases may have morphologic and immunohistochemical properties of a typical DLBCL, although no reliable morphologic fea- tures are seen on cytology $[9,10,22,35]$. Finally, doublehit lymphomas are usually characterized by complex karyotypes, highly aggressive behavior, and a poor prognosis [35]. MYC translocations are best documented using appropriate FISH probes rather than by PCR. In summary, on the basis of FNC/FC data, FISH may be conveniently used on LN FNC samples to achieve a definitive classification of NHL. The use of cytospin could optimize the preparations of multiple slides useful for multiple tests, including FISH assays. However, FISH chromosomal abnormalities are usually investigated when a specific pathological entity is highly suspected or has already been diagnosed since very few translocations are shared among different entities; therefore, specific chromosomal abnormalities are not routinely investigated to determine clonality in different B-cell lymphoproliferative processes [10].

\section{PCR-Based Assays}

PCR-based molecular tests are routinely used in lymphoproliferative processes for the identification, characterization and quantification of lymphomatous cells. The most common applications of PCR are the identification and quantification of translocations by qRT-PCR strategies, Ig and TCR rearrangements by clonality testing, and the identification of IGVH (IG variable segment of heavy chain) somatic hypermutations either by Sanger sequencing, single-strand conformational polymorphisms or RTPCR strategies (fig. 1,2). All these procedures are generally chosen based on the different requests, the availability of the corresponding technologies and the experience of each laboratory. Corresponding technologies have been used on any type of sample, such as paraffin-embedded tissues, fresh cells or tissues, and even cells obtained by FNC and cryopreserved or stored on FTA cards $[8$, 36-43].

The most frequent NHL translocations identified by PCR assays are the $t(14,18)$ ( $\mathrm{q} 32 ; \mathrm{q} 21)$, involving the BCL2IGH loci, and the $\mathrm{t}(11 ; 14)(\mathrm{q} 13 ; \mathrm{q} 32)$, involving the BCL1IGH loci, which occur in $60-70 \%$ of FL and in $30-40 \%$ of MCL [43], respectively. The $t(14 ; 18)$ occurs in $90 \%$ of FL and $20 \%$ of DLBCL [43]. As a consequence of this translocation, the BCL2 gene from the $18 \mathrm{q} 21$ locus is placed under the control of the IGH-Em enhancer, resulting in the deregulation of the BCL2 apoptotic pathway. In particular, in most MCLs, the BCL1 breakpoints are clustered on an 85-bp region of chromosome 11, named as the major translocation cluster region, and $\mathrm{JH}$ break- 
points lie on IGH genes juxtaposing the IGH-Em enhancer to chromosome 11q13 sequences. As a result of the translocation, the cyclin D1 gene is constitutively activated [43]. PCR for the detection of both of these translocations is routinely used on embedded or frozen tissues and has also been successfully applied to FNC samples $[43,44]$. Because of consistent differences in primers, procedures and results utilized in different laboratories, BIOMED-2 was established. BIOMED-2 is a consortium of multiple institutions that has standardized the BCL1/ $\mathrm{JH}$ and $\mathrm{BLC} 2 / \mathrm{JH}$ tests by validating primers and PCR systems among the participants and many groups outside the consortium as well [43]. BIOMED-2 Multiplex PCR strategies utilize a consensus $\mathrm{JH}$ primer in combination with a single BCL1 primer and nine BCL2 primers, respectively achieving a sensitivity of $10^{-3}$ and $10^{-4}$ on agarose gel. In addition to having diagnostic purposes, these translocations are investigated to evaluate the minimal residual disease by qRT-PCR assay in NHL follow-up [45-47].

Ig and TCR antigen receptor gene rearrangements are the mostly applied targets for clonality testing in NHL $[42,43,48-50]$. Ig and TCR rearrangements occur in the earliest stages of $\mathrm{B}$ and $\mathrm{T}$ cell development by the random joining of many $\mathrm{V},(\mathrm{D})$ and $\mathrm{J}$ genes in a unique $\mathrm{V}(\mathrm{D}) \mathrm{J}$ exon that encodes the final antigen-binding moiety of the Ig or TCR chain [51]. Therefore, each lymphocyte has a unique antigen receptor molecule on its cell membrane. Conversely, identical rearrangements cannot occur in independently generated cells but reflect the clonality of a lymphoid cell population. These differences largely dependent on the number of $\mathrm{N}$ sequences added by the terminal deoxynucleotidyl transferase, at the time of $\mathrm{V}-(\mathrm{N})$ (D)-(N)-J rearrangement [43]. Monoclonal Ig and TCR gene rearrangements are distinguished from the polyclonal ones by the homogeneity of PCR size compared to the heterogeneity of the different-sized fragments in polyclonal cell populations, and distinguish benign from lymphomatous cell proliferations. Clonality analysis has been defined in the EuroClonality/BIOMED-2 consortium by the standardization of multiplex PCR assays for nearly all Ig/TCR targets (IgK and TCR $\beta$, incomplete IGH D-J and TCRB D-J rearrangements). These tests collectively show a high rate of detection in the most common B- and T-cell lymphomas [41-43, 48, 49]. EuroClonality/ BIOMED-2 have also produced guidelines for the interpretation and for reporting results in suspected lymphoma [37]. In clinical practice, these procedures are generally used when histology and immunohistochemistry are equivocal or difficult to perform [37, 43], but have also

Lymph Node Fine-Needle Cytology:

Beyond Flow Cytometry been used on cytological samples, including nodal and extranodal FNC samples [36, 52, 53]. In particular, IGH/ TCR PCR can confirm FNC/FC diagnoses of lymphoma or assess polyclonality, adding clinical value to the FNC diagnoses of nodal and extranodal processes [40, 54]. Mayall et al. [55] maintain that, because of its high efficiency and short turnaround time, IGH/TCR PCR may replace FC on FNC samples, whereas Davidson et al. [56] suggested that their combined use should be advisable because of a relatively high rate of monoclonality detection by PCR only. Maroto et al. [4] stressed that IGH/TCR PCR enhances the LN FNC and FC diagnosis and cautioned on the risk of false positives and negatives by using a single primer pair PCR amplification over seminested methods. False positives and negatives of IGH PCR also occurred on FNC samples in another early investigation [44]. Therefore, to avoid this inconvenience, the combined use of IGH and BCL2 PCR has been suggested [44]. Moreover, new procedures and EuroClonality/ BIOMED-2 guidelines have improved PCR specificity, reducing dramatically the risk of false negatives and positives on both tissues and FNC samples [36]. TCR-PCR has been less utilized on FNC samples of T-cell NHL whereas corresponding diagnoses are generally more complex than those of the B-cell counterpart $[52,53]$. In particular, TCR-PCR may be extremely useful in cutaneous lymphoma staging by the corresponding NHL FNC [57] or in cerebrospinal fluid evaluation [52].

Another application of the PCR clonality tests is the identification of somatic hypermutations of Ig gene variable regions. These mutations are physiologically important in the affinity maturation of antibodies, and their frequencies in vivo are generally high enough to provide sufficient point mutations to generate a large number of different antibodies. IGVH mutations are characterized by single base-pair substitutions in the RGYW hotspot motifs, often resulting in amino acid changes. IGVH hypermutations have different clinical applications; in fact, they are considered a reliable prognostic marker in B-cell chronic lymphocytic leukemia (B-CLL) because hypermutated patients have a longer survival than nonmutated B-CLL patients. The hypermutation rate of human BL is approximately 10-fold less than the normal [43]. Different methods for a rapid detection of mutated $\mathrm{VH}$ region genes have been developed, including single-strand conformational polymorphism, direct sequencing of PCR products and denaturing high-performance liquid chromatography $[58,59]$; however, to the best of our knowledge, there is no experience of IGVH testing on the FNC samples reported. 


\section{High-Throughput Technologies-Based Arrays}

High-throughput technologies (HTT) encompass numerous and different new technologies that share the capacity of multiple molecular target investigations and sample processing in a fast and reproducible manner. The development of fast and simultaneous multiple molecular investigations has allowed the search for global genomic alterations responsible for the development and progression of different neoplasms, including lymphoma, with important clinical implications. The number and applications of these technologies are large and variable, as are their potential clinical applications. The most utilized HTT in biomedical research are gene expression profiling (GEP), comparative genomic hybridization (CGH), single-nucleotide polymorphism (SNP) arrays and next-generation sequencing (NGS) technologies (fig. 1,2). An exhaustive description of these technologies is impossible in the present article, where only the general principles and applications are summarized.

GEP has been conceived for the study of RNA and DNA changes, including chromosomal copy number alterations, genotyping and epigenetic modifications [60]. GEP platforms consist of numerous oligonucleotide probes immobilized on a solid surface, hybridized with DNA/RNA samples $[60,61]$. The signal obtained by the fluorochrome-labeled DNA/RNA reflects the concentration of the corresponding transcript, can be quantified $[60,62]$ and is able to measure a high number of genes simultaneously $[60,61]$. The resulting data can be analyzed and validated by bioinformatic tools and other technologies, such as PCR or immunohistochemistry, and in other additional independent series of samples. GEP analysis of NHL provides information on the corresponding different subtypes, revealing how each displays a unique gene expression program where the genes involved in different pathways are potential therapeutic targets [60]. The incorporation of GEP array information requires the extraction of good-quality DNA and RNA from tissues or blood, and often the need for fresh samples is a logistic challenge that is difficult to overcome in routine practice. Therefore, not surprisingly, FNC samples have been conveniently used for the GEP of different tumors [63, 64], including lymphomas [65], exploiting the specific advantages of FNC - namely to harvest vital tumor cells avoiding stroma, fat and other nontumor components. GEP improves the current prognostic indexes based on clinical criteria, such as the International Prognostic Index (IPI) $[60,66]$, because the corresponding GEP-based prognostic models are different in each pathological entity. Information generated by GEP may be translated into clinical practice when specific genetic or phenotypic features are associated with different GEP profiling. One of the major contributions of GEP has been the identification of two major subgroups of DLBCL, namely the germinal center type (GCB) and the activated $B$ cell $(A B C)$, since the gene expressions of germinal center cells are detected in GCB-DLBCL and the expression pattern of mitogenically activated $B$ cells with a secretory function are detected in ABC-DLBCL $[60,67$, 68]. The latter also shows the constitutive activation of the NFkB pathway through BCR signaling, with acquired activating mutations in CD79a, CARD11, and MYD88 and with inactivating mutations of the NFKB inhibitor A20, which are absent in GCB-DLBCL $[60,69,70]$. The different gene profiling tools determine prognostic and predictive differences, with relevant clinical impacts that may be reproduced by specific immunophenotypic profiles utilized to classify single cases in clinical practice $[71,72]$. GEP data need to be confirmed by other analyses, including NGS or in vitro studies in which the target genes are cloned into cell lines to evaluate their effective role in the start and/or progression of NHL. Bodor et al. [73] compared and confirmed the FL expression data obtained by the Lymphoma/Leukemia Molecular Profiling Project (LLMPP) using NGS. The high-throughput sequencing showed that the mutations in the SET domain of the EHZ2 gene act in a dominant fashion by increasing H3K27 trimethylation, which confers a gain of function and involves EHZ2 in tumorigenesis. These SET mutations are stable during disease progression, and thus represent a good therapy monitoring target [73]. Again dealing with GEP data confirmation, Iqbal et al. [74] confirmed the MYC target microRNAs in GCB- and ABC-DLBCL, identified by GEP signature, direct sequencing and in vitro studies. The in vitro analysis confirmed that the high expression of miR-155 is associated with $\mathrm{R}-\mathrm{CHOP}$ treatment failure and suggests different treatment options for resistant DLBCL. Finally, the information generated by GEP may be confirmed and translated into clinical practice by FISH, qPCR or other mRNA detection techniques $[60,75]$.

The CGH technique is carried out with high-density long (50-75 mer) oligonucleotide arrays, labeled with different fluorochromes, covering the whole genome with probes spaced about $1-5 \mathrm{~kb}$ apart. Oligonucleotide arrays competitively hybridize the normal chromosome metaphase of tumoral DNA and reference normal DNA of the same gender (possibly from the same individual). The different intensity of the hybridized tumoral and normal 
DNA signals indicates the gains or losses in specific chromosomal regions. In this manner, CGH detects unbalanced DNA copy number changes and small alterations, such as copy number variants (CNV) - considered gains or losses in tumoral DNA. CNV are DNA segments of 1 $\mathrm{kb}$ or larger, in single-copy tandem duplication or in complex gains/losses/inversions of homologous sequences. CNV are present in a variable copy number between tested DNA and a reference genome. CNVs are responsible for most individual genetic variations [60]. The systematic analysis of chromosomal imbalances by $\mathrm{GCH}$ has shown that most NHL carry a high number of secondary chromosomal alterations other than those targeting specific oncogenes, such as BCL2, MYC and CCND1 [60]. These secondary chromosomal alterations seem to be specific for different NHL entities and even for different patients suffering from the same NHL. Therefore, CGH might have a role in defining the biological behavior of different patients suffering from the same NHL subtype $[60,76]$. CGH has shown frequent deletions in $13 q$ and $11 \mathrm{q}$, gains of the 12 and $3 \mathrm{q}$ and losses of $1 \mathrm{p}$ chromosomes in MCL $[60,77]$. In CLL, CGH has shown the same deletions of MCL, but not the gains of $3 q$ and the losses of $1 p$ $[60,77]$. In ABC-DLBCL, CGH has shown gains or trisomy of 3 and gains of $18 \mathrm{q}$ chromosomes [60, 78, 79]. In GCB-DLBCL, CGH showed the gains of $2 p$ chromosome that are uncommon in ABC-DLBCL. Differences in genomic profiles have also been observed in different types of peripheral T-cell and NK cell NHL [79]. Like other types of HTT, CGH needs high-quality DNA that can be easily obtained by FNC. Consequently, FNC has been used to harvest cells from different tumors to perform CGH [80-82], whereas no experiences on LN FNC CGH are so far available.

SNP arrays use short oligonucleotides $(25$ mer $)$ as probes to distinguish different genotypes on the basis of the different number and distribution of SNPs. Signals of the same areas from different genomes are unique because they are differently covered by corresponding probes, which are able to identify CNV, uniparental disomy (UPD) and DNA copy-neutral loss of heterozygosity. UPDs are different chromosomal alterations that may occur through different mechanisms. The most frequent UPD is generated by the deletion of one allele and the correction of the defect by the duplication of the remaining allele. Consequently, the mutated allele is reduced to homozygosity after the deletion of the normal allele and the duplication of the mutated one [60]. The DNA copy-neutral loss of the heterozygosity is represented by stretches of DNA where both strands are identical and, therefore,

Lymph Node Fine-Needle Cytology:

Beyond Flow Cytometry all the SNPs are homozygous. The reduced intensity of the hybridization signal identifies the presence of two identical strands of DNA in the regions covered, revealing the homozygosity generated by the deletion of the corresponding chromosomal region. SNP arrays on many NHL types have revealed the following: (1) the deletion of several genes of the Hippo signaling pathway in MCL, with loss of proliferation and apoptosis control $[60,83]$; (2) the deletions at known chromosomal fragile sites that confirm the NHL genomic instability [60, 84]; (3) the significantly high CNV and segmental duplications in the regions flanking somatic UPD in MCL, suggesting that these regions may facilitate DNA recombination; (4) the inactivation of TP53 or CDKN2A in $17 \mathrm{p}$ or $9 \mathrm{p} 21$, respectively, with direct implications for the patient's outcome $[60,77,79]$, and (5) large gains of chromosome 3 in ABCDLBCL and MCL $[60,77,79]$. As a consequence, SNP arrays in NHL show that genomic complexity is an important and independent prognostic parameter $[60,77]$. To avoid missing the small clones that are important in the evolution of NHL, high-quality DNA is needed, which may be obtained by blood spots on FTA Whatman cards [85] or by FNC [86]. Consequently, FNC has been used to harvest cells from different tumors, such as choroidal melanoma, where high-density SNP arrays were more effective than FISH in detecting chromosome 3 aberrations and monosomy [86], although no experience with NHL is so far available.

NGS technologies are a fast, relatively inexpensive and versatile tool with which to analyze the mutational spectrum in NHL [60]. All the methodologies developed require DNA fragmentation, subsequent amplification of generated multiple fragments and their simultaneous sequencing in parallel, producing millions of sequenced reads for each given position of the genome, which are then aligned against the reference genome. The number of reads per stretch of DNA is called the coverage [60]. A high coverage is useful to detect tumor mutations in samples where there is some contamination of the normal cells, as in NHL, since it is able to filter out errors and noise. A high coverage may generate bias that can be avoided using reliable bioinformatic algorithms to interpret the sequences. A number of reads above or below the mean coverage per DNA region indicates the presence of gains, amplifications and hemizygous or homozygous deletions [60]. In addition to these large structural alterations, NGSs detect translocations, single nucleotide changes, somatic mutations, individual polymorphisms, small insertions or deletions (indels) using whole genome, whole transcriptome (WT), exome (specific re- 
gions of the genome including all coding exons) and specific-targeted genomic region sequencing strategies [60, 87]. WT or RNA sequencing starts with mRNA, total RNA, microRNAs, or other RNA cDNA, and quantify transcripts, disclose new fusion transcripts or alternative splice form transcripts. Exome and specific-targeted genomic regions are based on a selective capture of the genomic fragments of interest using tagged complementary oligonucleotides and can be used to minimize costs and increase speed by reducing the volume of data to analyze. All NGS methodologies can be performed on different platforms, such as Ion Torrent (Applied Biotechnologies), the 454 GS-Junior (Roche), semiconductor-based Ion Personal Genome Machine Sequencer, HiSeq 2000 Illumina, GAIIx Illumina, MiSeq Illumina, and others. The data obtained with NGS need to be confirmed by additional functional and clinical investigations. NGS WG, WT, exome and specific-targeted genomic region sequencing have been carried out in CLL $[60,87,88]$, HCL [60], FL $[60,89]$, DLBCL $[60,89]$ and plasma cell myeloma $[60,90]$. These studies have shown that in most NHL cases the mutations lie in a few genes, tend to cluster in common pathways depending on the NHL type and cell of origin, are not specific, and that the same mutations may occur in different NHL subtypes. In CLL, NGS has demonstrated that mutations in the genes of NOTCH1 signaling, RNA splicing, and processing machinery, inflammatory response, DNA damage and cell cycle control, and WNT pathways are differently distributed in IGVH-mutated and unmutated CLL. Conversely, IGVH hypermutations are equally distributed [60]. In DLBCL, NGS has confirmed the mutational data in ABC concerning CD79b, MYD88, A20 inhibitor, BCR signaling and $\mathrm{NF \kappa B}$ pathway mutations, and in GCB concerning BCL2 and EZH2, obtained with the HTT described above [60, 89]. NGS has also highlighted new mutations in the histone methyltransferase MLL2 (in 32\% of DLBCL and 89\% of FL cases) [60]. Other mutations detected lie on EZH2, MLL2, CREBBP, BRAF, B2M and EP300 (involved in the chromatin remodeling pathway). Other mutated genes identified by NGS are involved in the postgerminal center differentiation program, in protein translation machinery (including genes of the unfolded protein responses) and in mechanisms of the normal plasma cell secretor function $[60,90]$. In T-cell NHL, NGS has shown a high mutation rate in STAT3, causing additional neutropenia and rheumatoid arthritis [60,91]. Many of the mutated genes have become therapeutic targets, as is the case of the BRAF inhibitors used in NHL where this gene is mutated [60]. Like in all other HTT, NGS requires good- quality DNA and RNA from tissues, blood or fresh samples, which are difficult to obtain in routine practice. Therefore, different NGS platforms use FNC to harvest cells from different tumors [92-100]. These studies demonstrated that NGS-based mutational profiling can be performed with a few nanograms of DNA $(\sim 40 \mathrm{ng} / \mu \mathrm{l})$, which can be easily obtained from FNC in different tumors [93-98]. Therefore, NGS may enhance the molecular FNC potential, providing mutational information on genes with high diagnostic and predictive relevance, such as EGFR, BRAF, K/N/HRAS, KIT, PTEN, CDKN2A, just to mention some, thus contributing to personalized therapies.

\section{LN FNC Cell Harvesting and Preparations for Molecular Studies and Molecular Alteration Detection in Routine Diagnosis}

The application of all the molecular procedures described above requires a sufficient amount of cells and corresponding good-quality genetic material. As previously reported, 10-40 ng of DNA/RNA generally represent a sufficient amount to perform any molecular study. In clinical practice the main problem is represented by the number of cells obtained by FNC and the corresponding genetic content. Corresponding amounts are not constant and depend on different factors, such as the size of the needles, the FNC technical procedures and the nature of the lesions. It has been calculated that, using 23-gauge needles, a mean of $4 \times 10^{6}$ cells is obtained by LN FNC, $2.5 \times 10^{6}$ from breast carcinoma and $1.65 \times 10^{6}$ from thyroid carcinoma [101]. Considering that $40 \mathrm{ng}$ of DNA/ RNA may be obtained from $4 \times 10^{6}$ cells, a couple of additional passes from LN FNC may be sufficient to obtain genetic material sufficient for any procedure. Considering the technical support, genetic material has been successfully obtained from different cytological supports, such as smears, cell blocks or cryopreseved cells [7, 36, $102,103]$. This variability in technical supports is due to the usage of archival material or FNC performed by clinicians for routine diagnostic purposes that is only subsequently utilized for retrospective molecular studies. In the case of LN FNC, cytopathologists should personally perform FNC, ROSE, additional passes and the disposal of diagnostic material. In this way the same material may be capitalized for different basic ancillary techniques (ICC, FC, FISH) and stored on different supports depending on the needs and the technical availability of the single laboratories $[36,104]$. 
Despite their high number, not all NGS-identified alterations can play a role in lymphoma genesis or can be used as biomarkers for therapy monitoring, prognostic and predictive evaluation, or as therapeutic targets. Moreover, to reduce costs and analysis time to make the detection of the new molecular alterations compatible with the routine diagnostic purposes, many other strategies have been set to rapidly analyze any molecular alterations in a high number of samples. These strategies are often conceived as detection of the targets by qRT-PCR amplification followed by Sanger sequencing. Other procedures discriminate samples harboring molecular alterations by DNA/RNA multiple quantitative amplifications, allelespecific PCR-based evaluations or fragment analysis discriminations. Park et al. [105] used a multiplex real-time PCR method that incorporates melting curve analysis (Real-Q assay) to detect the BRAF V600E mutation in FNC samples of papillary thyroid carcinoma. The results obtained were comparable to those produced by an allelespecific PCR-based kit using dual-priming oligonucleotides (AS-PCR). da Cunha Santos et al. [8] used DNA retrieved from lung carcinoma FNC stored on Whatman FTA cards to detect small in-frame deletions in EGFR exon 19, using fragment analysis of fluorescently labeled PCR products subjected to ABI genetic analyzer capillary electrophoresis and sequencing. The same samples were then used to detect the EGFR exon 21 L858R mutation and exon 2 deletion of KRAS by direct sequencing. This study demonstrated that FTA cards could maximize and simplify sample storing for multiple mutational analyses providing high molecular weight DNA in sufficient amounts and quality. Saieg et al. $[7,38]$ and da Cunha Santos et al. [106] investigated the mutational status of EZH2, CD79B and MYD88 in B-cell NHL using DNA from FNC stored on FTA cards $[7,38]$ and DNA extracted from archival cytospin preparations previously tested at the time of diagnosis for the presence of MYC rearrangement and/or IGH/BCL2 translocation [106]. Samples harboring mutations were identified by MassARRAY spectrometry followed by Sanger sequencing. MassARRAY is a high-throughput multiplex spectrometry that permits mutation profiling and SNP genotyping by the simultaneous detection of multiple mutations. In conclusion, the application of high-throughput multiplex platforms, other than NGS, on minimal samples, such as FNC samples, reinforces the idea that these tests exponentially increase sample availability for molecular analysis and may facilitate future studies on NHL-related molecular events, in addition to assisting the design of individualized therapies.

\section{References}

1 van Dongen JJM, Lhermitte L, Bottcher S, Almeida J, van der Velden VHJ, Flores-Montero J, Rawstron A, Asnafi V, Lécrevisse Q, Lucio P, Mejstrikova E, Szczepanski T, Kalina T, de Tute R, Bruggemann M, Sedek L, Cullen M, Langerak AW, Mendonca A, Macintyre E, Martin-Ayuso M, Hrusak O, Vidriales MB, Orfao A; EuroFlow Consortium (EU-FP6, LSHB-CT-2006-018708): EuroFlow antibody panels for standardized $n$-dimensional flow cytometric immunophenotyping of normal, reactive and malignant leukocytes. Leukemia 2012;26:1908-1975.

2 Matsushita H, Nakamura N, Tanaka Y, et al: Clinical and pathological features of B-cell non-Hodgkin lymphomas lacking the surface expression of immunoglobulin light chains. Clin Chem Lab Med 2012;50:1665-1670.

3 Zeppa P, Vigliar E, Cozzolino I, et al: Fine needle aspiration cytology and flow cytometry immunophenotyping of non-Hodgkin lymphoma: can we do better? Cytopathology 2010;21:300-310.

4 Maroto A, Martinez M, Martinez MA, de Agustin P, Rodriguez-Peralto JL: Comparative analysis of immunoglobulin polymerase chain reaction and flow cytometry in fine nee- dle aspiration biopsy differential diagnosis of non-Hodgkin B-cell lymphoid malignancies. Diagn Cytopathol 2009;37:647-653.

-5 Bangerter M, Brudler O, Heinrich B, Griesshamnuer M: Fine needle aspiration cytology and flow cytometry in the diagnosis and subclassification of non-Hodgkin's lymphoma based on the World Health Organization classification. Acta Cytol 2007;51:390398.

-6 Schmid S, Tinguely M, Cione P, Moch H, Bode B: Flow cytometry as an accurate tool to complement fine needle aspiration cytology in the diagnosis of low grade malignant lymphomas. Cytopathology 2011;22:397-406.

7 Saieg MA, Geddie WR, Boerner SL, et al: $\mathrm{EZH} 2$ and $\mathrm{CD} 97 \mathrm{~B}$ mutational status over time in B-cell non-Hodgkin lymphomas detected by high-throughput sequencing using minimal samples. Cancer Cytopathol 2013; 121:377-386

8 da Cunha Santos G, Liu N, Tsao MS, et al: Detection of EGFR and KRAS mutations in fineneedle aspirates stored on Whatman FTA cards: is this the tool for biobanking cytological samples in the molecular era? Cancer Cytopathol 2010;118:450-456.
-9 Ochs RC, Bagg A: Molecular genetic characterization of lymphoma: application to cytology diagnosis. Diagn Cytopathol 2012;40: 542-555.

10 Zeppa P, Sosa Fernandez LV, Cozzolino I, Ronga V, Genesio R, Salatiello M, Picardi M, Malapelle U, Troncone G, Vigliar E: Immunoglobulin heavy-chain fluorescence in situ hybridization-chromogenic in situ hybridization DNA probe split signal in the clonality assessment of lymphoproliferative processes on cytological samples. Cancer Cytopathol 2012;120:390-400.

-11 da Cunha Santos G, Ko HM, Geddie WR, Boerner SL, Lai SW, Have C, Kamel-Reid S, Bailey D: Targeted use of fluorescence in situ hybridization (FISH) in cytospin preparations: results of 298 fine needle aspirates of $\mathrm{B}$-cell non-Hodgkin lymphoma. Cancer $\mathrm{Cy}$ topathol 2010;118:250-258.

12 Zhang S, Abreo F, Lowery-Nordberg M, Veillon DM, Cotelingam JD: The role of fluorescence in situ hybridization and polymerase chain reaction in the diagnosis and classification of lymphoproliferative disorders on fineneedle aspiration. Cancer Cytopathol 2010; 118:105-112.
Lymph Node Fine-Needle Cytology:

Beyond Flow Cytometry
Acta Cytologica 2016;60:372-384 DOI: $10.1159 / 000447734$ 
13 Monaco SE, Teot LA, Felgar RE, Surti U, Cai G: Fluorescence in situ hybridization studies on direct smears: an approach to enhance the fine-needle aspiration biopsy diagnosis of Bcell non-Hodgkin lymphomas. Cancer Cytopathol 2009;117:338-348.

14 Caraway NP, Thomas E, Khanna A, Payne L, Zhang HZ, Lin E, Keating MJ, Katz RL: Chromosomal abnormalities detected by multicolor fluorescence in situ hybridization in fineneedle aspirates from patients with small lymphocytic lymphoma are useful for predicting survival. Cancer Cytopathol 2008;114:315322.

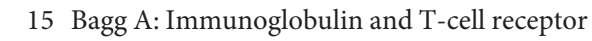
gene rearrangements: minding your B's and T's in assessing lineage and clonality in neoplastic lymphoproliferative disorders. J Mol Diagn 2006;8:426-429; quiz 526-527.

16 Richmond J, Bryant R, Trotman W, Beatty B, Lunde J: FISH detection of $t(14 ; 18)$ in follicular lymphoma on Papanicolaou-stained archival cytology slides. Cancer 2006;108:198204.

17 Safley AM, Buckley PJ, Creager AJ, et al: The value of fluorescence in situ hybridization and polymerase chain reaction in the diagnosis of B-cell non-Hodgkin lymphoma by fine-needle aspiration. Arch Pathol Lab Med 2004; 128:1395-1403.

$\checkmark 18$ Zeppa P, Marino G, Troncone G, et al: Fineneedle cytology and flow cytometry immunophenotyping and subclassification of nonHodgkin lymphoma: a critical review of 307 cases with technical suggestions. Cancer $\mathrm{Cy}$ topathol 2004;102:55-65.

19 Salaverria I, Zettl A, Bea S, et al: Specific secondary genetic alterations in mantle cell lymphoma provide prognostic information independent of the gene expression-based proliferation signature. J Clin Oncol 2007;25: 1216-1222.

-20 Ko HM, Geddie WR, Boerner SL, Rogalla P, da Cunha Santos G: Cytomorphological and clinicopathological spectrum of pulmonary marginal zone lymphoma: the utility of immunophenotyping, PCR and FISH studies. Cytopathology 2014;25:250-258.

-21 Elkins CT, Wakely PE Jr: Cytopathology of 'double-hit' non-Hodgkin lymphoma. Cancer Cytopathol 2011;119:263-271.

-22 Bentz JS, Rowe LR, Anderson SR, Gupta PK, McGrath CM: Rapid detection of the $t(11 ; 14)$ translocation in mantle cell lymphoma by interphase fluorescence in situ hybridization on archival cytopathologic material. Cancer 2004;102:124-131.

-23 Gong Y, Caraway N, Gu J, Zaidi T, Fernandez R, Sun X, Huh YO, Katz RL: Evaluation of interphase fluorescence in situ hybridization for the $t(14 ; 18)(\mathrm{q} 32 ; \mathrm{q} 21)$ translocation in the diagnosis of follicular lymphoma on fine-needle aspirates: a comparison with flow cytometry immunophenotyping. Cancer 2003;99:385393.
24 Shin HJ, Thorson P, Gu J, Katz RL: Detection of a subset of CD30+ anaplastic large cell lymphoma by interphase fluorescence in situ hybridization. Diagn Cytopathol 2003;29:6166.

-25 Tzankov A, Schneider A, Hoeller S, Dirnhofer S: Prognostic importance of BCL6 rearrangements in diffuse large B-cell lymphoma with respect to Bcl6 protein levels and primary lymphoma site. Hum Pathol 2009;40:10551056; author reply 1056.

26 Baro C, Espinet B, Salido M, et al: Cryptic $I G H / B C L 2$ rearrangements with variant FISH patterns in follicular lymphoma. Leuk Res 2011;35:256-259.

27 Chen YH, Gao J, Fan G, Peterson LC: Nuclear expression of sox11 is highly associated with mantle cell lymphoma but is independent of $\mathrm{t}(11 ; 14)(\mathrm{q} 13 ; \mathrm{q} 32)$ in non-mantle cell B-cell neoplasms. Mod Pathol 2010;23:105-112.

28 Streubel B, Vinatzer U, Lamprecht A, Raderer $\mathrm{M}$, Chott A: $\mathrm{T}(3 ; 14)(\mathrm{p} 14.1 ; \mathrm{q} 32)$ involving IGH and FOXP1 is a novel recurrent chromosomal aberration in MALT lymphoma. Leukemia 2005;19:652-658.

29 Katzenberger T, Kienle D, Stilgenbauer S, et al: Delineation of distinct tumour profiles in mantle cell lymphoma by detailed cytogenetic, interphase genetic and morphological analysis. Br J Haematol 2008;142:538-550.

30 Hallek M, Cheson BD, Catovsky D, et al: Guidelines for the diagnosis and treatment of chronic lymphocytic leukemia: a report from the International Workshop on Chronic Lymphocytic Leukemia updating the National Cancer Institute-Working Group 1996 guidelines. Blood 2008;111:5446-5456.

31 Sáez A, Andreu FJ, Seguí MA, Baré ML, Fernández S, Dinarés C, Rey M: HER-2 gene amplification by chromogenic in situ hybridisation (CISH) compared with fluorescence in situ hybridisation (FISH) in breast cancer - a study of two hundred cases. Breast 2006;15: 519-527.

32 Cavazzini F, Hernandez JA, Gozzetti A, et al: Chromosome 14q32 translocations involving the immunoglobulin heavy chain locus in chronic lymphocytic leukaemia identify a disease subset with poor prognosis. Br J Haematol 2008;142:529-537.

33 Baro C, Salido M, Domingo A, et al: Translocation $\mathrm{t}(9 ; 14)(\mathrm{p} 13 ; \mathrm{q} 32)$ in cases of splenic marginal zone lymphoma. Haematologica 2006;91:1289-1291.

34 Hwang Y, Lee JY, Mun YC, Seong CM, Chung WS, Huh J: Various patterns of IgH deletion identified by FISH using combined IgH and IgH/CCND1 probes in multiple myeloma and chronic lymphocytic leukemia. Int J Lab Hematol 2011;33:299-304.

35 da Cunha Santos G, Ko HM, Saieg MA, Boerner SL, Lai SW, Bailey D, Geddie WR: Cytomorphologic findings of B-cell lymphomas with concurrent $I G H / B C L 2$ and $M Y C$ rearrangements (dual-translocation lymphomas). Cancer Cytopathol 2011;119:254-262.
36 Peluso AL, Cozzolino I, Bottiglieri A, Lucchese L, Di Crescenzo RM, Langella M, Selleri C, Zeppa P: Immunoglobulin heavy and light chains and T-cell receptor beta and gamma chains PCR assessment on cytological samples: a study comparing FTA cards and cryopreserved lymph node fine-needle cytology. Cytopathology 2016, in press.

37 Langerak AW, Groenen PJTA, Brüggemann $\mathrm{M}$, et al: EuroClonality/BIOMED-2 guidelines for interpretation and reporting of Ig/ TCR clonality testing in suspected lymphoproliferations. Leukemia 2012;26:2159-2172.

38 Saieg MA, Geddie WR, Boerner SL, et al: The use of FTA cards for preserving unfixed cytological material for high-throughput molecular analysis. Cancer Cytopathol 2012;120: 206-214.

- 39 Berget E, Helgeland L, Molven A, Vintermyr OK: Detection of clonality in follicular lymphoma using formalin-fixed, paraffin-embedded tissue samples and BIOMED-2 immunoglobulin primers. J Clin Pathol 2011;64:37-41.

40 Zeppa P, Cozzolino I, Peluso AL, et al: Flow cytometry and molecular assessment of lymphoid infiltrate in fine-needle cytology samples of Hashimoto thyroiditis. Cancer Cytopathol 2009;117:174-184.

41 van Krieken JHJM, Langerak AW, Macintyre EA, Kneba M, Smith JL, Garcia Sanz R, et al: Improved reliability of lymphoma diagnostics via PCR-based clonality testing: report of the BIOMED-2 Concerted Action BHM4CT98-3936. Leukemia 2007;21:201-206.

42 Langerak AW, Molina TJ, Lavender FL, et al: Polymerase chain reaction based clonality testing in tissue samples with reactive lymphoproliferations: usefulness and pitfalls - a report of the BIOMED-2 Concerted Action BMH4CT98-3936. Leukemia 2007;21:222-229.

43 van Dongen JJ, Langerak AW, Bruggemann $\mathrm{M}$, et al: Design and standardization of PCR primers and protocols for detection of clonal immunoglobulin and T-cell receptor gene recombinations in suspect lymphoproliferations: report of the BIOMED-2 Concerted Action BMH4-CT98-3936. Leukemia 2003; 17:2257-2317.

44 Grosso LE, Collins BT: DNA polymerase chain reaction using fine needle aspiration biopsy smears to evaluate non-Hodgkin's lymphoma. Acta Cytol 1999;43:837-841.

45 Rambaldi A, Carlotti E, Oldani E, Della Starza I, Baccarani M, Cortelazzo S, Lauria F, Arcaini L, Morra E, Pulsoni A, Rigacci L, Rupolo M, Zaja F, Zinzani PL, Barbui T, Foa R: Quantitative PCR of bone marrow BCL2/IgH+ cells at diagnosis predicts treatment response and long-term outcome in follicular non-Hodgkin lymphoma. Blood 2005; 105:3428-3433.

46 Dik WA, Pike-Overzet K, Weerkamp F, De Ridder D, De Haas EF, Baert MRM, et al: New insights on human T-cell development by quantitative $\mathrm{T}$-cell receptor gene rearrangement studies and gene expression profiling. J Exp Med 2005;201:1715-1723. 
-47 Ståhlberg A, Aman P, Ridell B, Mostad P, Kubista M: Quantitative real-time PCR method for detection of B-lymphocyte monoclonality by comparison of kappa and lambda immunoglobulin light chain expression. Clin Chem 2003;49:51-59.

-48 Patel KP, Pan Q, Wang Y, Maitta RW, Du J, Xue X, et al: Comparison of BIOMED-2 versus laboratory-developed polymerase chain reaction assays for detecting $\mathrm{T}$-cell receptorgamma gene rearrangements. J Mol Diagn 2010;12:226-237.

49 Evans PAS, Pott C, Groenen PJTA, Salles G, Davi F, Berger F, et al: Significantly improved PCR-based clonality testing in B-cell malignancies by use of multiple immunoglobulin gene targets: report of the BIOMED-2 Concerted Action BHM4-CT98-3936. Leukemia 2007;21:207-214.

50 McClure RF, Kaur P, Pagel E, Ouillette PD, Holtegaard CE, Treptow CL, et al: Validation of immunoglobulin gene rearrangement detection by PCR using commercially available BIOMED-2 primers. Leukemia 2006;20:176179.

-51 van Zelm MC, van der Burg M, de Ridder D, Barendregt $\mathrm{BH}$, de Haas EF, Reinders MJ, et al: Ig gene rearrangement steps are initiated in early human precursor B cell subsets and correlate with specific transcription factor expression. J Immunol 2005; 175:5912-5922.

52 Tembhare P, Yuan CM, Morris JC, Janik JE, Filie AC, Stetler-Stevenson M: Flow cytometric immunophenotypic assessment of T-cell clonality by $\mathrm{v} \beta$ repertoire analysis in fine-needle aspirates and cerebrospinal fluid. Am J Clin Pathol 2012;137:220-226.

53 Venkatraman L, Catherwood MA, Patterson A, Lioe TF, McCluggage WG, Anderson NH: Role of polymerase chain reaction and immunocytochemistry in the cytological assessment of lymphoid proliferations. J Clin Pathol 2006;59:1160-1165.

54 Cozzolino I, Vigliar E, Todaro P, Peluso AL, Picardi M, Sosa Fernandez LV, Mignogna MD, Tuccari G, Selleri C, Zeppa P: Fine needle aspiration cytology of lymphoproliferative lesions of the oral cavity. Cytopathol 2014;25:241-249.

-55 Mayall F, Johnson S: Immunoflow cytometry compared with PCR for the identification of clonality in FNAs of T-cell-rich B-cell lymphomas. Cytopathology 2007;18:117-119.

- 56 Davidson B, Risberg B, Berner A, Smeland EB, Torlakovic E: Evaluation of lymphoid cell populations in cytology specimens using flow cytometry and polymerase chain reaction. $\mathrm{Di}$ agn Mol Pathol 1999;8:183-188.

57 Vigliar S, Cozzolino I, Picardi M, et al: Lymph node fine-needle cytology in the staging and follow-up of cutaneous lymphomas. BMC Cancer 2014;14:8-18.

58 Bardwell PD, Martin A, Scharff MD: Mutation detection of immunoglobulin $\mathrm{V}$-regions by DHPLC. J Immunol Methods 2002;266: 165-173.
Xiao W, Oefner PJ: Denaturing high-performance liquid chromatography: a review. Hum Mutat 2001;17:439-474.

60 Campo E: Whole genome profiling and other high throughput technologies in lymphoid neoplasms - current contributions and future hopes. Mod Pathol 2013;26:S97-S110.

61 Iqbal J, Liu Z, Deffenbacher K, et al: Gene expression profiling in lymphoma diagnosis and management. Best Pract Res Clin Haematol 2009;22:191-210.

62 Shi L, Reid LH, Jones WD, et al: The MicroArray Quality Control (MAQC) project shows inter- and intraplatform reproducibility of gene expression measurements. Nat Biotechnol 2006;24:1151-1161.

63 Annaratone L, Marchiò C, Renzulli T, Castellano I, Cantarella D, Isella C, Macrì L, Mariscotti G, Balmativola D, Cantanna E, Deambrogio C, Pietribiasi F, Arisio R, Schmitt F, Medico E, Sapino A: High-throughput molecular analysis from leftover of fine needle aspiration cytology of mammographically detected breast cancer. Transl Oncol 2012;5: 180-189.

64 Roepman P, Schuurman A, Delahaye LJ, Witteveen AT, Floore AN, Glas AM: A gene expression profile for detection of sufficient tumour cells in breast tumour tissue: microarray diagnosis eligibility. BMC Med Genomics 2009;2:52.

65 Morrison C, Palatini J, Riggenbach J, Radmacher M, Porcu P: Fine-needle aspiration biopsy of non-Hodgkin lymphoma for use in expression microarray analysis. Cancer 2006; 108:311-318

66 Read JA, Koff JL, Nastoupil LJ, Williams JN, Cohen JB, Flowers CR: Evaluating cell-of-origin subtype methods for predicting diffuse large B-cell lymphoma survival: a meta-analysis of gene expression profiling and immunohistochemistry algorithms. Clin Lymphoma Myeloma Leuk 2014;14:460-467.

67 Lenz G, Wright G, Dave SS, et al: Stromal gene signatures in large-B-cell lymphomas. N Engl J Med 2008;359:2313-2323.

68 Rosenwald A, Wright G, Wiestner A, et al: The proliferation gene expression signature is a quantitative integrator of oncogenic events that predicts survival in mantle cell lymphoma. Cancer Cell 2003;3:185-197.

69 Karube K, Nakagawa M, Tsuzuki S, et al: Identification of FOXO3 and PRDM1 as tumor-suppressor gene candidates in NK-cell neoplasms by genomic and functional analyses. Blood 2011;118:3195-3204.

70 Compagno M, Lim WK, Grunn A, et al: Mutations of multiple genes cause deregulation of NF- $\mathrm{BB}$ in diffuse large B-cell lymphoma. Nature 2009;459:717-721.

71 Visco C, Li Y, Xu-Monette ZY, et al: Comprehensive gene expression profiling and immunohistochemical studies support application of immunophenotypic algorithm for molecular subtype classification in diffuse large B-cell lymphoma: a report from the International
DLBCL Rituximab-CHOP Consortium Program Study. Leukemia 2012;26:2103-2113, erratum in Leukemia 2014;28:980.

72 Hans CP, Weisenburger DD, Greiner TC, et al: Confirmation of the molecular classification of diffuse large B-cell lymphoma by immunohistochemistry using a tissue microarray. Blood 2004;103:275-272.

73 Bodor C, Grossmann V, Popov N, Okosun J, O'Riain C, Tan K, Marzec J, Araf S, Wang J, Lee AM, Clear A, Montoto S, Matthews J, Iqbal S, Rajnai H, Rosenwald A, Ott G, Campo E, Rimsza LM, Smeland EB, Chan WC, Braziel RM, Staudt LM, Wright G, Lister TA, Elemento O, Hills R, Gribben JG, Chelala C, Matolcsy A, Kohlmann A, Haferlach T, Gascoyne RD, Fitzgibbon J: EZH2 mutations are frequent and represent an early event in follicular lymphoma. Bood 2013;122:31653168.

74 Iqbal J, Shen Y, Huang X, Liu Y, Wake L, Liu C, Deffenbacher K, Lachel CM, Wang C, Rohr J, Guo S, Smith LM, Wright G, Bhagavathi S, Dybkaer K, Fu K, Greiner TC, Vose JM, Jaffe E, Rimsza L, Rosenwald A, Ott G, Delabie J, Campo E, Braziel RM, Cook JR, Tubbs RR, Armitage JO, Weisenburger DD, Staudt LM, Gascoyne RD, McKeithan TW, Chan WC: Global microRNA expression profiling uncovers molecular markers for classification and prognosis in aggressive B-cell lymphoma. Blood 2015;125:1137-1145.

-75 Rimsza LM, Wright G, Schwartz M, et al: Accurate classification of diffuse large B-cell lymphoma into germinal center and activated B-cell subtypes using a nuclease protection assay on formalin-fixed, paraffin-embedded tissues. Clin Cancer Res 2011;17: 3727-3732.

76 Ferreira BI, Garcia JF, Suela J, et al: Comparative genome profiling across subtypes of lowgrade B-cell lymphoma identifies type-specific and common aberrations that target genes with a role in B-cell neoplasia. Haematologica 2008;93:670-679.

77 Royo C, Salaverria I, Hartmann EM, et al: The complex landscape of genetic alterations in mantle cell lymphoma. Semin Cancer Biol 2011;21:322-334.

-78 Rinaldi A, Mian M, Chigrinova E, et al: Genome-wide DNA profiling of marginal zone lymphomas identifies subtype-specific lesions with an impact on the clinical outcome. Blood 2011;117:1595-1604.

79 Lenz G, Wright GW, Emre NC, et al: Molecular subtypes of diffuse large B-cell lymphoma arise by distinct genetic pathways. Proc Natl Acad Sci USA 2008;105:13520-13525.

$>_{80}$ Vieira J, Henrique R, Ribeiro FR, Barros-Silva JD, Peixoto A, Santos C, Pinheiro M, Costa VL, Soares MJ, Oliveira J, Jerónimo C, Teixeira MR: Feasibility of differential diagnosis of kidney tumors by comparative genomic hybridization of fine needle aspiration biopsies. Genes Chromosomes Cancer 2010;49: 935-947.
Lymph Node Fine-Needle Cytology:

Beyond Flow Cytometry
Acta Cytologica 2016;60:372-384 DOI: $10.1159 / 000447734$ 
81 Andre F, Job B, Dessen P, Tordai A, Michiels S, Liedtke C, Richon C, Yan K, Wang B, Vassal G, Delaloge S, Hortobagyi GN, Symmans WF, Lazar V, Pusztai L: Molecular characterization of breast cancer with high-resolution oligonucleotide comparative genomic hybridization array. Clin Cancer Res 2009;15: 441-451.

-82 Kitoh H, Ryozawa S, Harada T, Kondoh S, Furuya T, Kawauchi S, Oga A, Okita K, Sasaki K: Comparative genomic hybridization analysis for pancreatic cancer specimens obtained by endoscopic ultrasonography-guided fineneedle aspiration. J Gastroenterol 2005;40: 511-517.

83 Hartmann EM, Campo E, Wright G, et al: Pathway discovery in mantle cell lymphoma by integrated analysis of high-resolution gene expression and copy number profiling. Blood 2010;116:953-961.

84 Bignell GR, Greenman CD, Davies H, et al: Signatures of mutation and selection in the cancer genome. Nature 2010;463:893-898.

-85 Fowler KE, Reitter CP, Walling GA, Griffin DK: Novel approach for deriving genome wide SNP analysis data from archived blood spots. BMC Res Notes 2012;5:503.

-86 Young TA, Burgess BL, Rao NP, Gorin MB, Straatsma BR: High-density genome array is superior to fluorescence in-situ hybridization analysis of monosomy 3 in choroidal melanoma fine needle aspiration biopsy. Mol Vis 2007;13:2328-2333.

87 Puente XS, Pinyol M, Quesada V, et al: Whole-genome sequencing identifies recurrent mutations in chronic lymphocytic leukaemia. Nature 2011;475:101-105.

88 Fabbri G, Rasi S, Rossi D, et al: Analysis of the chronic lymphocytic leukemia coding genome: role of NOTCH1 mutational activation. J Exp Med 2011;208:1389-1401.

89 Morin RD, Mendez-Lago M, Mungall AJ, et al: Frequent mutation of histone-modifying genes in non-Hodgkin lymphoma. Nature 2011;476:298-303.

90 Chapman MA, Lawrence MS, Keats JJ, et al: Initial genome sequencing and analysis of multiple myeloma. Nature 2011;471:467472.

91 Koskela HL, Eldfors S, Ellonen P, et al: Somatic STAT3 mutations in large granular lymphocytic leukemia. N Engl J Med 2012; 366:1905-1913.
92 Gleeson FC, Kipp BR, Voss JS, Campion MB, Minot DM, Tu ZJ, Klee EW, Sciallis AP, Graham RP, Lazaridis KN, Henry MR, Levy MJ: Endoscopic ultrasound fine-needle aspiration cytology mutation profiling using targeted next-generation sequencing: personalized care for rectal cancer. Am J Clin Pathol 2015; 143:879-888.

93 Gleeson FC, Kipp BR, Kerr SE, Voss JS, Lazaridis KN, Katzka DA, Levy MJ: Characterization of endoscopic ultrasound fine-needle aspiration cytology by targeted next-generation sequencing and theranostic potential. Clin Gastroenterol Hepatol 2015;13:37-41.

-94 Le Mercier M, D'Haene N, De Nève N, Blanchard O, Degand C, Rorive S, Salmon I: Next-generation sequencing improves the diagnosis of thyroid FNA specimens with indeterminate cytology. Histopathology 2015;66: 215-224.

95 Kubota Y, Kawakami H, Natsuizaka M, Kawakubo K, Marukawa K, Kudo T, Abe Y, Kubo K, Kuwatani M, Hatanaka Y, Mitsuhashi T, Matsuno Y, Sakamoto N: CTNNB1 mutational analysis of solid-pseudopapillary neoplasms of the pancreas using endoscopic ultrasound-guided fine-needle aspiration and next-generation deep sequencing. J Gastroenterol 2015;50:203-210.

96 de Biase D, Visani M, Baccarini P, Polifemo AM, Maimone A, Fornelli A, Giuliani A, Zanini N, Fabbri C, Pession A, Tallini G: Next generation sequencing improves the accuracy of KRAS mutation analysis in endoscopic ultrasound fine needle aspiration pancreatic lesions. PLoS One 2014;9:e87651.

97 Kanagal-Shamanna R, Portier BP, Singh RR, Routbort MJ, Aldape KD, Handal BA, Rahimi H, Reddy NG, Barkoh BA, Mishra BM, Paladugu AV, Manekia JH, Kalhor N, Chowdhuri SR, Staerkel GA, Medeiros LJ, Luthra R, Patel KP: Next-generation sequencing-based multi-gene mutation profiling of solid tumors using fine needle aspiration samples: promises and challenges for routine clinical diagnostics. Mod Pathol 2014;27:314-327.

98 Young G, Wang K, He J, Otto G, Hawryluk M, Zwirco Z, Brennan T, Nahas M, Donahue A, Yelensky R, Lipson D, Sheehan CE, Boguniewicz AB, Stephens PJ, Miller VA, Ross JS: Clinical next-generation sequencing successfully applied to fine-needle aspirations of pulmonary and pancreatic neoplasms. Cancer Cytopathol 2013;121:688-694.
99 Hadd AG, Houghton J, Choudhary A, Sah S, Chen L, Marko AC, Sanford T, Buddavarapu K, Krosting J, Garmire L, Wylie D, Shinde R, Beaudenon S, Alexander EK, Mambo E, Adai AT, Latham GJ: Targeted, high-depth, next-generation sequencing of cancer genes in formalin-fixed, paraffin-embedded and fine-needle aspiration tumor specimens. J Mol Diagn 2013;15:234-247.

100 Lee HB, Joung JG, Kim J, Lee KM, Ryu HS Lee HO, Moon HG, Park WY, Noh DY, Han W: The use of FNA samples for whole-exome sequencing and detection of somatic mutations in breast cancer surgical specimens. Cancer Cytopathol 2015;123:669-677.

101 Rajer M, Kmet M: Quantitative analysis of fine needle aspiration biopsy samples. Radiol Oncol 2005;39:269-272.

102 Kanagal-Shamanna R, Portier BP, Singh RR, Routbort MJ, Aldape KD, Handal BA, Rahimi H, Reddy NG, Barkoh BA, Mishra BM, Paladugu AV, Manekia JH, Kalhor N, Chowdhuri SR, Staerkel GA, Medeiros LJ, Luthra R, Patel KP: Next-generation sequencing-based multi-gene mutation profiling of solid tumors using fine needle aspiration samples: promises and challenges for routine clinical diagnostics. Mod Pathol 2014;27:314-327.

103 Dyhdalo K, Macnamara S, Brainard J, Underwood D, Tubbs R, Yang B: Assessment of cellularity, genomic DNA yields, and technical platforms for BRAF mutational testing in thyroid fine-needle aspirate samples. Cancer Cytopathol 2014;122:114-122.

104 Peluso AL, Cascone AM, Lucchese L, Cozzolino I, Ieni A, Mignogna C, Pepe S, Zeppa P: Use of FTA cards for the storage of breast carcinoma nucleic acid on fine-needle aspiration samples. Cancer Cytopathol 2015; 123:582-592.

105 Park KS, Oh YL, Ki CS, Kim JW: Evaluation of the Real-Q BRAF V600E detection assay in fine-needle aspiration samples of thyroid nodules. J Mol Diagn 2015; 17:431-437.

106 da Cunha Santos G, Saieg MA, Ko HM, Geddie WR, Boerner SL, Craddock KJ, Crump $\mathrm{M}$, Bailey D: Multiplex sequencing for EZH2, CD79B, and MYD88 mutations using archival cytospin preparations from Bcell non-Hodgkin lymphoma aspirates previously tested for MYC rearrangement and IGH/BCL2 translocation. Cancer Cytopathol 2015;123:413-420. 